\title{
DA AUTONOMIA AO APRISIONAMENTO: A faceta conservadora e os ataques ao patrono da educação brasileira
}

\author{
Rafael de Farias Ferreira
} Jorge Fernando Hermida

Resumo

Nos últimos anos Paulo Freire passou de patrono da educação à “energúmeno", "ídolo de esquerda". Essa radical, mas processual, mudança de posicionamento, ocasionou repercussões de proporção internacional. O que gerou um encadeamento de opiniões em torno da legitimidade das obras e da importância de Freire para a educação. Para entender o alto teor subjetivista empregado nessa situação, o ensaio busca compreender por que motivos estão contestando e execrando desde o golpe jurídico-midiático-parlamentar de 2016 o legado do educador brasileiro. O estudo orientado pelo materialismo histórico-dialético busca a partir do que está aparente identificar a essência das ações. Nesse sentido, a conjuntura política e econômica são bases que desvelam os ataques como parte do conjunto de estratégias que procuram inserir as políticas educacionais na lógica do mercado. O momento histórico atual evidencia o aprofundamento de programas direcionadas ao uso de técnicas que flexibilizam o ensino, controlam os tempos pedagógicos e o ambiente escolar. Os ataques a Freire são formas de imobilizar os movimentos que resistem e lutam para impedir o projeto de desmonte da educação pública.

Palavras-chave: Paulo Freire; conservadorismo; neoliberalismo; fascismo.

FROM AUTONOMY TO RESTRAINT: The conservative facet and the attacks to the patron of brazilian education

\begin{abstract}
In recent years, Paulo Freire has gone from being a patron of education to being an "ignorant", "idol of the left-wing". This radical, but procedural, change of position had repercussions of international proportions. It generated a chain of opinions surrounding the legitimacy of Freire's works and his importance for education. To understand the high subjectivist content employed in this situation, the essay seeks to understand why they have been contesting and decrying the legacy of the Brazilian educator since the 2016 legal-media-parliamentary coup. The study guided by historical-dialectical materialism seeks, based on what is evident, to identify the essence of actions. In this sense, the political and economic situation are bases that unveil the attacks as part of the set of strategies that seek to insert educational policies into the logic of the market. The current historical moment shows the deepening of programs aimed at the use of techniques that make teaching more flexible, control teaching hours and the school environment. The attacks on Freire are ways to immobilize the movements that resist and fight to prevent the project to dismantle public education.
\end{abstract}

Keywords: Paulo Freire; conservatism; neoliberalism; fascism.

\section{DE LA AUTONOMÍA A LA RESTRICCIÓN:} La faceta conservadora y los ataques al patrón de la educación brasileña

Resumen

En los últimos años, Paulo Freire ha pasado de ser una referencia en la defensa de la educación a ser un "ignorante", "ídolo de la izquierda". Este cambio de posición radical, pero procedimental, tuvo repercusiones de proporciones internacionales. Se generó una cadena de opiniones en torno a la legitimidad 
de las obras de Freire y su importancia para la educación. Para comprender el alto contenido subjetivista empleado en esta situación, el ensayo busca comprender por qué han estado impugnando y denunciando el legado del educador brasileño desde el golpe legal-mediático-parlamentario de 2016. El estudio guiado por el materialismo histórico-dialéctico busca, a partir de lo evidente, identificar la esencia de las acciones. En este sentido, la situación política y económica son bases que develan los ataques como parte del conjunto de estrategias que buscan introducir las políticas educativas en la lógica del mercado. El momento histórico actual muestra la profundización de programas orientados al uso de técnicas que flexibilicen la docencia, controlen los horarios lectivos y el entorno escolar. Los ataques a Freire son formas de inmovilizar a los movimientos que resisten y luchan para impedir el proyecto de desmantelamiento de la educación pública.

Palabras clave: Paulo Freire; conservatismo; neoliberalismo; fascismo.

\section{INTRODUÇÃO}

Incomoda à burguesia brasileira conservadora, racista e misógina saber que um menino que nasceu no Recife, em Pernambuco, "lá no Nordeste" tenha se tornado referência para o mundo construindo suas primeiras leituras a partir do chão de casa e do quintal rodeado de mangueiras. Arroyo ao poetizar o prefácio do livro de Brandão (2014) apresenta a história de Freire como a história de meninos e meninas do campo que querem ler o mundo.

Essa capacidade de mobilizar as massas para emancipação humana e política marcou a trajetória do professor que em 2012 recebeu o título de patrono da educação brasileira e, três anos depois teria sua obra e sua imagem, enquanto intelectual, contestada, inicialmente, nos movimentos de rua. O ensaio busca compreender o porquê dessa dinâmica de ataques contra Freire, que por ter ganhado espaço na grande mídia, gerou demonstrações de protestos mais também, de concordância, a tal ponto que foi necessário desenvolver um estudo sobre esse fenômeno.

Nesse sentido organizamos três ciclos de diálogo. O primeiro sintetiza a importância de Paulo Freire para a educação no seu sentido teórico e prático. O segundo busca expor a rede que manifesta os ataques reacionários com o intuito de conhecer os personagens que das multidões ou do anonimato tiveram os seus rostos e suas vozes evidenciados no momento crucial da crise econômica. O terceiro procura a essência explicativa que permite a partir do processo histórico dos acontecimentos econômicos e políticos interpretar a reconfiguração capitalista e o retorno da faceta conservadora com feições fascistas.

Vivemos um dos piores momentos da democracia brasileira. Sabendo disso, não podemos deixar que a desproblematização do futuro numa compreensão mecanicista da história cause a morte ou a negação autoritária da utopia (FREIRE, 2011). O estudo pretende desvelar o que pode estar por detrás das ofensas, discriminação que imobiliza as massas e ataca os que se dedicaram a pensar a transformação do mundo.

\section{NOTAS SOBRE PAULO FREIRE, O PATRONO DA EDUCAÇÃO BRASILEIRA}

O educador que se alfabetizou no chão do quintal de sua casa, à sombra das mangueiras, com palavras do seu mundo, aprendeu ler a vida por meio do diálogo existencial. Diálogo que busca situar os sujeitos "a realidade social, objetiva, que não existe por acaso, mas como produto da ação dos homens, que também não se transforma por acaso" (FREIRE, 2005, p. 41).

Essa forma de aprender a ler o mundo possibilita aos marginalizados enunciar a construção de suas palavras. Palavras que quando somada com a ação é significação produzida pela práxis, em 
DOI: $10.12957 /$ teias.2021.62056

outros termos, a consciência de si como pessoa que vive e produz a sua existência, a partir dos modos operantes do capital.

No texto que relembra os cinquenta anos da publicação do livro Pedagogia do Oprimido, Arroyo (2019, p. 03) afirma que Paulo Freire prioriza "ver, reconhecer, os Outros como sujeito de voz, sujeitos de saberes, culturas, consciência”. Esses por estarem aprisionados em uma lógica que explora a força de trabalho sofrem opressão e passam a ter a sua humanidade negada, o que os impedem de compreender e agir na realidade em que estão imersos. Não sem razão, Freire (2013, p. 129) denuncia que

Nem todos temos a coragem deste encontro (do encontro com o povo) e nos enrijecemos no desencontro, no qual transformamos os outros em puros objetos. E, ao assim procedermos, nos tornamos necrófilos, em lugar de biófilos. Matamos a vida, em lugar de alimentarmos a vida. Em lugar de buscá-la, corremos dela. Matar a vida, freá-la, com a redução dos homens a puras coisas, aliená-los, mistificá-los, violentá-los são o próprio dos opressores.

E na contramão dessa racionalização, que a obra de Freire busca superar o pensamento político e pedagógico que oculta a história das relações entre opressores-oprimidos. Por esse motivo a universalidade de seus escritos decorrem da aliança teoria-prática. Porque não é possível "aos esfarrapados do mundo e aos que neles se descobrem e, assim descobrindo-se, com eles sofrem mas, sobretudo com eles lutam" (FREIRE, 2005, p. 23) transmutar a realidade sem nela produzir as condições necessárias para a transformação. Agrega-se a essa concepção, experiência vivida, trabalho, pedagogia e política como dimensões basilares na construção pedagógica que se entrelaçou com as experiências de alfabetização e de mobilização das camadas populares. Nas palavras de Gadotti (1996, p. 80)

a obra de Paulo Freire pode ser vista tomando-o seja como cientista, seja como educador. Contudo, essas duas dimensões supõem uma outra: Paulo Freire não as separa da política. Paulo Freire deve ser considerado também como político. Esta é a dimensão mais importante da sua obra. Ele não pensa a realidade como um sociólogo que procura apenas entendê-la. Ele busca, nas ciências (sociais e naturais), elementos para, compreendendo mais cientificamente a realidade, poder intervir de forma mais eficaz nela. Por isso ele pensa a educação ao mesmo tempo como ato político, como ato de conhecimento e como ato criador.

Ao contrapor a ordem hegemônica que regula o mundo e as relações antagônicas, Freire (2011) opta por uma prática educativa progressista orientada para a emancipação humana, para a liberdade dos povos e à justiça social entre homens e mulheres, para a democracia autêntica como soberania popular.

Bertrand (2001) ao apresentar as teorias da educação desenvolvidas a nível global, evidência a obra de Freire, como principal referência das Teorias Sociais da Educação, em específico, nas Pedagogias da Conscientização. O autor explica que esta teoria é formada por subgrupos, como por exemplo, o da Educação Cooperativa e das Pedagogias Críticas, denominadas de Pedagogias da Libertação. É nesse conjunto de grupos que está situada a perspectiva freireana, a qual propõe vincular a teoria com a prática e defende o desenvolvimento de um processo de conscientização sociocultural em que os estudantes adquirem a consciência das problemáticas concretas existentes em seu contexto histórico-social-cultural e libertam-se da dominação das classes dominantes. 
O seu pensamento e sua dedicação a educação lhe conferiram títulos e prêmios . "Foi reconhecido mundialmente pela sua práxis educativa através de numerosas homenagens. Além de ter seu nome adotado por muitas instituições. É cidadão honorário de várias cidades no Brasil e no exterior. A Paulo Freire foi outorgado inúmeros títulos de doutor honoris causa" (GADOTTI; ABRÃO, 2012, p.12). Das várias titulações que lhes foram conferidas, destacamos a de Patrono da Educação Brasileira, proposta originalmente pela deputada Luiza Erundina (PSB-SP) e instituída pela Lei $n^{\circ}$ 12.612, de 13 de abril de 2012, no governo de Dilma Rousseff.

As notas apresentadas aqui expõem de forma sintética que a educação para Freire é fundamental na reinvenção do mundo, sendo ela, uma recusa a "domesticação" das mentes, dos corpos e do tempo, que na pós-modernidade, aos olhos do educador, "transforma o futuro num pré-dado, que já se conhece" (FREIRE, 2001, p. 11).

O pensamento de Freire se revela como um condutor revolucionário que desvela a importância da educação a favor da emancipação dos sujeitos que vivem à margem da sociedade. Ao se compreenderem no mundo as pessoas entendem que "não há utopia verdadeira fora da tensão entre denuncia de um presente tornando-se cada vez mais intolerável e o anúncio de um futuro a ser criado, construído, política, estética e eticamente, por nós, mulheres e homens" (2011, p. 126).

E por incrível que pareça a burguesia da ala política e os empresários oportunistas tem maior clareza do que os educadores do potencial revolucionário do legado freiriano. Não foi sem razão que o governo do Presidente Luiz Inácio Lula da Silva e da Presidente Dilma Rousseff criaram programas e plataformas tendo como referência o professor Paulo Freire. Mas, comungamos com a afirmação de José Eustáquio Romão que em entrevista à BBC Brasil fez a seguinte declaraçãó ${ }^{2}$ :

Paulo Freire nunca foi aplicado na educação brasileira. (...) Ele entra (nas universidades) como frase de efeito, como título de biblioteca, nome de salão. As suas ideias e suas propostas metodológicas serviram de base para políticas púbicas de diversos países, mas ainda se resumem a experiências pontuais no Brasil (COSTA, 2015).

Com efeito, o Brasil, enquanto nação, perdeu a possibilidade de implementar nas políticas e nas escolas públicas uma perspectiva teórica social com base nas pedagogias da conscientização e da libertação. O jogo de disputa, entre Estado e mercado, impediu aos governos de esquerda, reparar historicamente, as acusações feitas pela ditadura e a interrupção do projeto de educação ${ }^{3}$ que entraria em curso se não fosse o golpe militar de 1964. Essa falta de assunção por parte do governo e dos movimentos populares que não conseguem se perceberem fragmentados, presos em suas especificidades, assim como as disciplinas escolares, impulsionaram uma onda de contestação que se semeia nos movimentos de junho de 2015 e que ainda permanece em curso. Não é curioso Paulo Freire ser atacado em um período de crise política e econômica? Tentemos compreender o porquê.

\footnotetext{
${ }^{1}$ Ver http://www.projetomemoria.art.br/PauloFreire/biografia/09_biografia_homenagens.html

${ }^{2}$ Disponível em: < https://www.bbc.com/portuguese/noticias/2015/07/150719_entrevista_romao paulofreire_cc $>$

3 Ele desenvolvia na época um programa nacional de alfabetização que seria implantado por João Goulart, inspirado em projeto que desenvolveu no Rio Grande do Norte com cerca de 400 jovens e adultos. A experiência na cidade de Angicos ganhou notoriedade internacional por se propor a concluir em 40 horas o processo de alfabetização e a formar cidadãos mais conscientes de seus direitos e dispostos a defendê-los de maneira democrática.
} 
DOI: $10.12957 /$ teias.2021.62056

\section{A ONDA DE CONTESTAÇÃO E EXECRAÇÃO DA OBRA E DO EDUCADOR PAULO FREIRE}

Os acontecimentos econômicos que vêm ocorrendo do desdobramento da crise financeira de 2007-2008, "caracterizado como um momento de reconfiguração do capitalismo e de aprofundamento do neoliberalismo sob nova forma" (GOUVÊA, 2020, p. 24) evidenciou o ódio da burguesia brasileira, oriunda da ascensão das camadas populares e, a força da política conservadora.

Muitos pesquisadores apontam essas evidências a partir do impeachment da Presidente Dilma Rousseff. Mas se voltarmos para as eleições de 2014 que assegurou a vitória democrática da candidata do PT, observaremos que o pedido do PSDB ao Tribunal Superior Eleitoral, de uma auditória especial da contagem de votos, já dava indícios do ressentimento de classe e da intensificação aos ataques ao Estado democrático ${ }^{4}$ (DAS AGÊNCIAS, 2014).

Em 2015, ocorre uma série de manifestações de rua, fenômeno complexo que necessita ser analisado dentro de uma perspectiva histórica, considerando que não se tratou de um movimento universal em termos ideológicos ou de intenções e propostas para o governo. Os cartazes, os gritos e as performances eram diversas e iam desde pedidos pela volta dos militares, até faixas pelo impeachment, entre dezenas de outros vociferações.

No protesto ocorrido no dia 15 de março, eis que surge uma faixa com a seguinte frase: Chega de doutrinação marxista. Basta de Paulo Freire. Essa faixa amplamente divulgada nas reder sociais provocou uma sequência de comentários que naquele momento parecia se tratar do "assunto" da semana, que assim como as fofocas sobre a vida dos famosos logo seria esquecido. No entanto, não foi o que aconteceu.

Os ataques se espelharam e os sujeitos imersos nas multidões foram ganhando rostos e espaços privilegiados. A Revista Fórum, a exemplo, quatro dias depois da manifestação, procurou o Professor de história Eduardo Sallenave, autor da faixa, que declarou não fazer o menor sentido a admiração de muitos brasileiros por Paulo Freire ${ }^{5}$. Segundo ele:

é um rostinho simpático para um projeto cruel e desumano. Um teórico totalmente alinhado ao marxismo e regimes tirânicos, como o de Fidel Castro. As pessoas pedem mais educação, mas o MEC segue a ideologia do PT. Criticar o Paulinho? Ah, isso não! Paulo Freire é uma figura sacrossanta! Haja saco... Pedagogia do Oprimido $=$ coitadismo e doutrinação marxista fulera; não recomendo nem para o meu cachorro (STREIT, 2015).

Esse tipo de depoimento vindo de um professor de história gerou um certo espanto aos especialistas em educação. O episódio marca a princípio uma aparente insatisfação da influência de Freire na educação brasileira. Com o golpe jurídico-midiático-parlamentar consumado em 31 de agosto de 2016 que impediu a então presidenta da república concluir o seu mandato, observamos dois movimentos. O primeiro, se configurou no abalo da democracia a tal ponto que trouxe para o cenário um grupo de políticos e empresários ultraconservadores que iriam mobilizar uma direita raivosa para uma "mudança radical da política", o que não deixou de acontecer. O segundo, os ataques desse grupo as conquistas sociais que as camadas populares obtiveram ao longo dos governos de esquerda.

\footnotetext{
${ }^{4}$ Disponível em: < https://www.gazetadopovo.com.br/vida-publica/psdb-contesta-a-reeleicao-de-dilma-eflg7jua9jt04gy7xpwpffsy6/>

${ }_{5}^{5}$ Disponível em: < https://revistaforum.com.br/noticias/professor-cria-polemica-em-protesto-contra-paulo-freire-pedagogia-do-oprimidoe-coitadismo/>
} 
A conjuntura do golpe expõe as indignações da burguesia "ofendida" que cria um movimento direitista, onde se agregam os neoliberais, os gerencialistas, os neoconservadores e os populistas autoritários (APPLE, 2003). Freire mais uma vez entra em palco, sofrendo ataques mais ostensivos.

O Olavo de Carvalho, filósofo e influenciador digital, que vive nos Estados Unidos desde 2005 e ministra cursos de filosofia transmitidos por vídeos na Internet é uma figura que vai ganhar notoriedade nesse contexto do movimento direitista. A sua posição ideológica de extrema direita e neoconservadora irá influenciar os seus discípulos nos ataques ao governo do PT e ao legado de Paulo Freire. Na sua rede social, no dia 01 de agosto de 2017, ele expõe um comentário sobre o livro "Descontruindo Paulo Freire", organizado por Thomas Giulliano Ferreira dos Santos. Olavo afirma que "o livro responde à necessidade, urgente de reduzir às suas verdadeiras dimensões o personagem que recebeu do governo petista o título de "patrono da educação brasileira" precisamente por nunca ter educado ninguém". Essa postagem irá ganhar vários comentários desrespeitosos, agressivos ao legado e a pessoa de Paulo Freire ${ }^{6}$. As acusações se integram ao um conjunto de narrativas que serão disseminadas pelo clã da família Bolsonaro que tem o Olavo de Carvalho como principal referência intelectual.

Por essa e outras razões, um dos principais censuradores de Paulo Freire é o atual Presidente Jair Bolsonaro, que no dia 15 de fevereiro de 2018, período em que era candidato à presidência da república, usou suas redes sociais para expor um trecho da entrevista concedida ao youtuber Nando Moura, no qual ele afirma: "Pra mudar, primeiro você tem que mandar Paulo Freire pro espaço. Essa forma de educar não deu certo". Ao compartilhar a imagem ${ }^{7}$, com a frase a esquerda e o seu rosto a direita, o candidato a presidente complementa:

Quem assumir em 2019 terá o grande desafio de acabar com o avançado processo de formação de militantes e massa de manobra implementado pela esquerda para o aumento de seu poder e controle. Quando nossa prioridade for o conhecimento, aí sim teremos a garantia de um futuro melhor! (BOLSONARO, 2018).

A narrativa expressada nas redes sociais é um ataque direto as conquistas que os grupos marginalizados obtiveram com a ascensão da esquerda ao poder. Existem análises críticas que mostram que o governo ao desenvolver uma política de conciliação de classe não alterou as condições históricas e materiais dos trabalhadores, ao contrário, intensificou as desigualdades devido a vários aspectos de submissão política e econômica. Concordamos com essas análises, no entanto, não descartamos os ganhos sociais que oportunizaram uma parte, mesmo que muito irrisória, dos trabalhadores a espaços da classe dominante (FERRAZ, 2019).

Ainda, durante a campanha eleitoral, em palestra para empresários no Espírito Santo, o então candidato afirmou: "A educação brasileira está afundando. Temos que debater a ideologia de gênero e a escola sem partido. Entrar com um lança-chamas no MEC para tirar o Paulo Freire de lá". E complementou: "Eles defendem que tem que ter senso crítico. Vai lá no Japão, vai ver se eles estão preocupados com o pensamento crítico"s (HADDAD, 2019). O posicionamento discursivo de Bolsonaro estabelece alinhamento com as relações antidemocráticas que no período eleitoral legitimou as práticas homofóbicas, racistas, misóginas e machistas do grupo de direita ao grupo da sociedade civil que compõem ou se simpatizam com as bandeiras de luta dos movimentos

\footnotetext{
${ }^{6}$ Ver em https://twitter.com/odecarvalho/status/892403039243571206

${ }^{7}$ Ver em: <https://twitter.com/jairbolsonaro/status/964217823408152579>

8 Disponível em: < https://www1.folha.uol.com.br/ilustrissima/2019/04/por-que-o-brasil-de-olavo-e-bolsonaro-ve-em-paulo-freire-uminimigo.shtml?origin=folha $>$
} 
sociais. Além disso, o contexto em que essa fala foi desenvolvida dava vestígios da adesão dos empresários a falta de decoro democrático do candidato.

A onda de ataques se fortaleceu com o surgimento da Escola Sem Partido, movimento que se apresentou a sociedade brasileira como "uma iniciativa conjunta de estudantes e pais preocupados com o grau de contaminação político-ideológica das escolas brasileiras, em todos os níveis: do ensino básico ao superior" (ESCOLA SEM PARTIDO, 2020). No site, do movimento, eles descrevem que o objetivo central é "dar visibilidade a um problema que atinge a imensa maioria das escolas e universidades brasileiras: a instrumentalização do ensino para fins ideológicos, políticos e partidários. E o modo de fazê-lo é divulgar o testemunho das vítimas, ou seja, dos próprios alunos" (ESCOLA SEM PARTIDO, 2020).

Com a vitória de Bolsonaro, nas eleições, vimos outros críticos ganharem espaço na grande mídia: seus filhos, Flávio e Eduardo Bolsonaro, Senador e Deputado Federal; Miguel Nagib, fundador da Escola Sem Partido; Rodrigo Constantino, colunista, presidente do Instituto Liberal e membro-fundador do Instituto Millenium; e o Abraham Weintraub, ex-ministro da educação. Eles fazem a defesa de uma educação sem ideologia empregando em seus discursos a ideologia da direita conservadora e vulgarmente vinculam Paulo Freire a fake news preconceituosas como a do suposto kit gay distribuído nas escolas. Por que disseminar tanto ódio em torno do intelectual e do Professor Paulo Freire? Por que difamá-lo por meio de calunias e críticas tão superficiais? São essas indagações que buscaremos compreender no próximo tópico desse ensaio.

\section{DESVELANDO AS INTENCIONALIDADES POR DETRÁS DOS ATAQUES A PAULO FREIRE}

"Energúmeno, Ídolo de esquerda, comunista bajulador de tirano que colocou o marxismo e a luta de classe para sala de aula". Essas foram palavras proferidas pelo Presidente Jair Bolsonaro, no dia 16 de dezembro de 2019, ao declarar o fim do contrato e o despejo da Associação de Comunicação Educativa Roquette Pinto (Acerp), responsável pela programação da TV Escola. Nessa declaração, o Presidente vinculou o conteúdo transmitido pelo canal a Paulo Freire e complementou dizendo: "era uma programação totalmente de esquerda, ideologia de gênero. Dinheiro público para ideologia de gênero. Então tem que mudar" (REDAÇÃO DA REVISTA FÓRUM, 2019).

Esse episódio soma-se com outras ações orquestradas pelo movimento direitista para estabelecer uma política conservadora e neoliberal no seu sentido mais perverso, considerando que nessa perspectiva política, a economia vale mais do que vidas e todas as coisas são consideradas mercadoria, inclusive a educação. Mas, é importante salientar que para chegar nesse estágio uma trajetória foi percorrida e é dela que resulta o retorno do conservadorismo com feições fascistas.

O surgimento do neoliberalismo, em meados de 1970, resulta do processo de restruturação do capital, que passou a defender a liberdade absoluta do mercado e a restrição da intervenção estatal. A globalização do capitalismo e o avanço tecnológico tornaram o acúmulo flexível, passando a atender demandas de nichos, sobrepondo a produção em série, de larga escala, que acumulava grandes estoques dirigidos ao consumo de massa (SAVIANI, 2011). Essa nova reorganização das relações produtivas se insere no Brasil, nos anos de 1990, no governo de Fernando Henrique Cardoso, sendo sua inserção tardia, mas avassaladora. Tão avassaladora que modificou a posição do Partido dos Trabalhadores em seu teor político-ideológico (LIRA; HERMIDA, 2017). 
Para ganhar as eleições de 2002, o PT de Lula teve que alinhar suas propostas com as expectativas do mercado. O documento basilar de sua campanha: a Carta ao povo brasileiro, na verdade era um atestado aos banqueiros estrangeiros e nacionais, aos credores das dívidas externa e interna, as frações da burguesia industrial penalizada pela política do governo FHC e aos latifundiários ligados ao agronegócio de que sua gestão estaria comprometida com a estabilidade da ordem econômica e política do país e, que para isso, aumentaria a competitividade internacional do Brasil. Só assim, o Presidente pode ser eleito (MACHADO, 2009).

Souza e Hoff (2019, p. 04) explicam que a política definida para o Brasil, no governo Lula e Dilma foi com base na perspectiva neodesenvolvimentista que se caracteriza por tomar como medidas a busca do crescimento econômico e social e o fortalecimento do capitalismo, "contando com programas de transferência de renda e atendendo a interesses das classes dominadas, em vez de romper radicalmente com a política neoliberalista do bloco político no poder". Os efeitos foram positivos até os impactos causados pela desregulação econômica e política oriunda de 2008.

A crise financeira de 2008 considerada a maior crise desde a grande depressão de 1929, "surgi, após o colapso da bolha imobiliária, foi alimentado pela expansão do crédito bancário e fortificado pela utilização de novos instrumentos financeiros" (CECHIN; MONTOYA, 2017, p. 167). Para Bresser-Pereira (2009, p. 133) esse contexto econômico e político:

É uma profunda crise de confiança decorrente de uma cadeia de empréstimos originalmente imobiliários baseados em devedores insolventes que, ao levar os agentes econômicos a preferirem a liquidez e assim liquidar seus créditos, estava levando bancos e outras empresas financeiras à situação de quebra mesmo que elas próprias estejam solventes.

Disso resultou um pânico entre as instituições financeiras que deram preferência pelo aumento significativo de liquidez". "A procura pela liquidez destruiu o processo de venda de ativos em grande escala, ocasionando a queda nos preços dos ativos financeiros e a contração do crédito bancário, tanto para transações comerciais, como para industriais" (CECHIN; MONTOYA, 2017, p. 167). Essa situação provocou a queda na produção industrial e no comércio internacional de modo global.

No Brasil, essa crise acarretou "desaceleração do crescimento ou mesmo uma recessão, com o aumento do desemprego e queda da renda; crescimento da inflação e fragilização financeira do Estado; piora das relações econômicas-financeiras internacionais do país, com ameaça de crise cambial" (FIGUEIRAS, 2017, p. 148).

O contexto de crise foi oportuno para ala da direita que orquestrou em uma grande jogada política, através das campanhas de denúncias ético-morais contra o governo, usando como pano de fundo a bandeira do combate a corrupção. Desse jogo político resulta-se o impeachment da Presidenta Dilma. A narrativa organizada pela Operação Lava Jato tornou-se a explicação mais

\footnotetext{
${ }^{9}$ Liquidez é um conceito que corresponde à facilidade e velocidade com as quais um ativo pode ser convertido em caixa. Ou, em uma definição mais simples, é a capacidade de transformar um ativo (bens ou investimentos) em dinheiro. A partir de tal contextualização, pode-se compreender que quanto mais rápida for a conversão do ativo em dinheiro, mais líquido ele será. Um ativo com pouca liquidez, portanto, é aquele mais difícil de ser convertido em dinheiro, seja simplesmente pela falta de compradores ou mesmo pelo tempo necessário para liquidar o investimento. A liquidez, na verdade, envolve duas dimensões: a facilidade de conversão e a perda de valor. Qualquer ativo pode ser convertido em caixa rapidamente, desde que seu valor seja reduzido. Mas um ativo com boa liquidez é aquele que pode ser convertido em dinheiro com rapidez, sem que haja uma perda significativa de valor. Fonte: BTG Pactual digital (2017).
} 
contundente para o agravamento da situação econômica do país, tirando de foco o cenário internacional que incidia fortemente nas regiões periféricas do mundo capitalista.

O processo inconstitucional do golpe colocou o PMDB (Partido do Movimento Democrático Brasileiro) de Michel Temer no comando e uma nova era se redesenhava. Era o retorno das políticas neoliberais nos moldes desenvolvimentistas que acabaria ocasionando a estagnação econômica e atingiria diretamente os setores de proteção social (SOUZA; HOFF, 2019).

E nesse cenário frutífero para o mercado e para a ala da direita que Bolsonaro e o seu grupo de apoiadores ascendem com o discurso da política antissistema. E como todos esses acontecimentos estão ligados a contestação do legado e à execração a Paulo Freire?

Para entender os ataques uma categoria é essencial, pois possibilita analisar os ásperos tempos em que vive a sociedade brasileira: o fascismo. Pelo fascismo revela-se uma leitura que permite avaliar o retorno do movimento conservador de direita na política, cuja violência e autoritarismo são instrumentos eficazes para a formação e consolidação da estrutura social desigual que se intensifica no governo do Bolsonaro (ZILIO; MIRANDA, 2020).

Konder (2009, p.25) nos alerta, que é necessário não banalizar a palavra fascismo através de discursos emocionados ou amplamente utilizada como efeito de agitação contra as injurias de um determinado sujeito ou grupo. O fascismo é um dos fenômenos políticos mais significativos do século XX e estamos experimentando uma nova onda nesse início de século XXI. Com efeito, o conceito não pode perder o rigor científico levando em consideração "as vantagens políticas de uma análise realista e diferenciada dos movimentos das forças que lhe são adversas". Para facilitar a compreensão argumentativa que exibe o conservadorismo intrínseco da direita, recorremos ao autor por apresentar caraterísticas operacionais e estratégicas do fascismo: a) pragmatismo radical; b) identidade da teoria e da prática; c) existência de um princípio sagrado/valor supremo para o engajamento e motivação de cidadãos.

O pragmatismo radical é percebido nos ataques a Paulo Freire a partir da propaganda simplista, sem formalismo e carregada de inautenticidade para o convencimento das camadas populares. Stanley (2018, p. 37) nos explica que "é difícil promover uma política que prejudicará um grande grupo de pessoas diretamente. O papel da propaganda é ocultar os objetivos claramente problemáticos de políticos ou movimentos políticos, mascarando-os com ideais amplamente aceitos". Uma vez que, "os conservadores sabem que, para uma política ser eficaz, ela precisa ser levada à prática através de iniciativas concretas, manobras, concessões, acordos, golpes de audácia, formas de arregimentação das forças disponíveis que transcendem da mera atitude doutrinária" (KONDER, 2009, p. 28). Nesse sentido, observa-se que o uso das redes sociais foi a principal forma de propagar a hostilização ao educador brasileiro.

A segunda característica é uma apropriação indevida da formulação de unidade da teoria e da prática de Marx. Konder (2009, p. 32) esclarece que para o autor toda produção cultural e todo pensamento significativo tem ligação com as condições materiais de vida e com as condições sociais do mundo determinado. Não há como analisar uma teoria fazendo abstração de seu uso social. Para os conservadores, a exemplo Mussolini, essa unidade é substituída pela identidade de teoria e prática. Com isso,

A teoria perde sua capacidade de "criticar" a prática: cortaram-lhe as asas, ela deixou de poder se elevar acima do solo onde surgia e se viu completamente instrumentalizada. Em lugar de se reconhecerem socialmente condicionadas (como em Marx), as verdades passaram a morrer, sistematicamente, pregadas na cruz da utilidade circunstancial que o cinismo dos fascistas encontrava para elas (KONDER, 2009, p. 33). 
Assim, o pensamento conservador procura minar o conteúdo teórico. Para os ideólogos de direita a teoria só tem valor se identificada com a prática. Mariategui (2012, p. 24) elucida que o fascismo "não se trata de um fenômeno cerebral; trata-se de um fenômeno irracional". É por isso, que a intelectualidade de Paulo Freire é esvaziada de sua epistemologia nos ataques feitos pelos conservadores. Não só a ele como ao intelectualismo e a universidade pública. Desde os movimentos de rua o conservadorismo substitui o debate fundamentado por medo e raiva. "Mentiras óbvias e repetidas fazem parte do processo pelo qual a política fascista destrói o espaço da informação" (STANLEY, 2018, p. 66).

A terceira vertente do pensamento autoritário de direita é o princípio sagrado do mito da pátria, que une as pessoas numa identidade nacional homogênea (ZILIO; MIRANDA, 2020). O próprio slogan do governo traz esse princípio de forma implícita: Pátria amada Brasil. Um exemplo dessa vertente pode ser notada em vários pronunciamentos do presidente. Mas, observaremos dois episódios de cunho fascista protagonizado pelo Ex-ministro da Educação, Abraham Weintraub, para evidenciar como o conservadorismo se manifesta nas performances discursivas que pautam as ações concretas de exploração da classe trabalhadora e de extermínio da pluralidade dos grupos minoritários. O primeiro ocorreu no dia 22 de abril de 2020, na reunião ministerial, citada pelo ExMinistro da Justiça Sergio Mouro em seu depoimento para Supremo Tribunal Federal.

Weintraub após escutar o relato da Ministra de Estado da Mulher, da Família e dos Direitos Humanos em torno dos povos indígenas, ciganos e quilombolas, esbravejou: "odeio o termo 'povos indígenas', odeio esse termo. Odeio. O 'povo cigano'. Só tem um povo nesse país. Quer, quer. Não quer, sai de ré. É povo brasileiro, só tem um povo. Pode ser preto, pode ser branco, pode ser japonês, pode ser descendente de índio, mas tem que ser brasileiro, pô! Acabar com esse negócio de povos e privilégios" (G1, 2020).

Esse fala reforça a política de homogeneização que desconsidera as diferenças e a diversidade que é a marca da existência do provo brasileiro. Nesse sentido, o nacional e o social estão contidos em um só, expressando a ideia de que é necessário recorrer ao princípio sagrado para unificar as pessoas em torno do mito da pátria.

No contexto brasileiro a vertente do princípio sagrado invocou também a moralidade cristã e os padrões tradicionais de família. Stanley (2018, p. 127) ressalta que o fascismo é hostil a "qualquer ameaça à masculinidade patriarcal e à família tradicional [...]. Essas ameaças incluem os crimes de estupro e agressão, assim como o chamado desvio sexual." E uma das armas empregadas pelo grupo conservador foi a ideia de que o MEC do governo petista havia distribuído Kits Gay para as escolas públicas. Mesmo essa informação tendo sido desmentida em cadeia nacional, o governo ainda insisti em relembrar o Kit gay e Paulo Freire.

Em sua rede social, o Abraham Weintraub, no dia 05 de março de 2020 escreve:

Paulo Freire e kit gay não têm vez no MEC do Pres. @jairbolsonaro. Vejam uma amostra do formato/conteúdo do material que o professor@CarlosNadalim preparou para as crianças. Querem saber mais? Sigam o prof. @CarlosNadalim, o novo rosto (e o primeiro sorriso) do ensino no Brasil.

Percebe-se claramente a crítica feita da maneira mais baixa possível, apelando para um discurso preconceituoso e homofônico que exalta a uma falsa valorização da moral cristã e de uma educação antifreiriana. É o discurso conservador na sua forma mais reacionária e abertamente avessa as liberdades democráticas. Na prática, o governo Bolsonaro expõe a sua faceta mais conservadora da política que tem como base as ideias de antipovo e antipluralidade, assim dizendo "não imaginam a coexistência dos sujeitos na sociedade senão por meio do autoritarismo ou pela 
produção de desigualdades. Fundamentado na ideologia ultraliberal, procura radicalizar cada vez mais a política, por meio de atitudes e decisões autoritárias" (HERMIDA; ORSO, 2020, p. 03).

Essa conjuntura nos leva a compreender que todos os acontecimentos pontuados nesse ensaio se caracterizam como um momento de reconfiguração do capitalismo e de aprofundamento do neoliberalismo sob nova forma, sendo ela, o modernizar a economia conservando os princípios da direita. Nesse contexto, fica evidente que a essência dos ataques a Paulo Freire não está apenas em degradar a sua imagem e sua produção intelectual. A contestação e à execração a Paulo Freire é uma espécie de camuflagem que encobre o esvaziamento teórico dos ideólogos, em outros termos, uma forma de manobrar a massa contra os últimos avanços obtidos na educação no governo anterior. As razões são de base econômica e:

\begin{abstract}
A disfuncionalidade que caracteriza a crise do capitalismo diz respeito à incapacidade de um determinado arranjo social da produção capitalista de manter os níveis de extração do mais-valor diante da queda na taxa de lucro e, ao mesmo tempo, manter sob controle os conflitos e os antagonismos sociais. Crise, portanto, refere-se aos mecanismos estruturais de exploração do trabalho, de circulação mercantil e de concorrência (ALMEIDA, 2019, p. 30).
\end{abstract}

Para alavancar o ideário neoliberal, os conservadores adequam as políticas educacionais as exigências do mercado, desapropriando os trabalhadores das condições sociais necessárias que possam garantir a produção da vida. Não obstante, as primeiras ações do governo foram diminuir drasticamente os gastos nas áreas de proteção social. Só a educação sofreu em $2020^{10}$, um corte de 19,8 bilhões ou seja, -16,3\% quando comparado com o orçamento de 2019 (Agência Senado, 2020).

Os cortes afetam toda a estrutura educacional e comprometem o direito à gratuidade e a educação como bem público. O governo promove uma onda de mazelas retirando verbas das ciências humanas, desqualificando os futuros professores, profissionais que irão formar os próximos profissionais, reitera o boicote aberto ao movimento estudantil e diminui os investimentos em ciências e tecnologias produzidos nas universidades públicas. Diminui as verbas para Educação Básica e passa a investir em políticas educacionais pautadas na pedagogia das competências (SOUZA; RODRGUES, 2020).

Essas ações vão de contra a todo conhecimento produzido por Freire. O fato de terem feito dele patrono da educação brasileira no governo Dilma foi determinante para fazê-lo de bode expiatório das ofensivas organizadas pela direita. Nessa acepção entende-se que essas ações fazem parte do plano de sucateamento total da educação pública, para implantar a alienação e controle da grande massa, como também, adequar as políticas educacionais ao projeto neoliberal vigente.

\title{
CONSIDERAÇÕES FINAIS
}

Compreender os fenômenos sociais que envolvem a educação pública em uma dinâmica em que "tudo o que é solido se desmancha no ar" (MARX \& ENGELS, 2008, p. 13) em questão de dias, horas ou segundos, se tornou imperativo2, para uma sociedade que tem suas relações, a título de exemplo, drasticamente modificadas, por uma pandemia3, que desvelou a fragilidade das engrenagens que movimentam o mundo, em especial, o Estado Brasileiro.

A educação não está livre desse processo de reconfiguração e da política conservadora. Algo que parecia ser um evento isolado, como a faixa exposta na manifestação de 2015, na verdade

\footnotetext{
${ }^{10}$ Em 2019, o orçamento do ministério da Educação era de R \$122,9 bilhões e para 2020, este valor é de apenas 103,1 bilhões.
} 
era o início de ataques orquestrados para superar a situação altamente insatisfatória da direita. Todos os ideólogos mencionados nesse ensaio procuraram desvalorizar a educação e as políticas educacionais do governo de esquerda, que mesmo tendo sido pautadas pelos organismos multilaterais, não deixou de incluir os cidadãos das camadas populares.

Nesse momento, temos um aprofundamento dos projetos direcionados ao uso técnicas que flexibilizem o ensino (a ampliação da educação a distância) e o outro marcado pela rigidez do ambiente escolar (militarização da escola) que atendem a objetivos comuns: a ultra-centralização da educação e o controle sobre corpos e mentes (SOARES, 2020).

Não é sem razão que o movimento escola sem partido vem insistindo para a aprovação do seu projeto de lei e, nesse sentido, é importante desvelar as contradições. Vimos que o movimento se descreve como uma iniciativa conjunta de estudantes e pais preocupados com o grau de contaminação político-ideológica das escolas brasileiras, em todos os níveis: do ensino básico ao superior, mas o site não divulga quem são esses pais e quem são esses alunos. Saviani (2020, p. 15) nos lembra que:

[...] agir como se a educação fosse isenta de influência política é uma forma eficiente de colocá-la a serviço dos interesses dominantes. E é esse o sentido do programa "escola sem partido" que visa subtrair a escola do que seus adeptos entendem como "ideologias de esquerda", colocando-a sob a influência da ideologia e dos partidos da direita, portanto, a serviço dos interesses dominantes.

Não é sem motivos, que temos um movimento de um só rosto, o advogado e procurador paulista Miguel Nagib, que em julho de 2020 anunciou que as atividades seriam suspensas "por absoluta falta de apoio" do governo Bolsonaro. Em entrevista ao jornal Estadão ele desabafou: "Sempre que falo em nome do Escola sem Partido procuro passar a impressão de que se trata de um trabalho coletivo, mas, na verdade, quem faz tudo sou eu" (TERRA, 2020). É a faceta fascista instalada em todos os setores que em via de regra democrática garantem o acesso aos direitos sociais.

Devemos ficar atentos a essas declarações, porque antes de sair do Ministério da Educação, o Weintraub indicou sete pessoas para compor o Conselho Nacional de Educação que foram nomeadas posteriormente.

A lista dos novos representantes do CNE inclui Tiago Tondinelli, olavista que foi chefe de gabinete do ex-ministro da Educação Ricardo Vélez; Valseni Braga, diretora do sistema Batista de Educação; e Gabriel Giannattasio, professor de história da Universidade Estadual de Londrina (UEL) que também agrada o grupo olavista. Esses vão integrar a câmara da educação básica do conselho. Outras pessoas ligadas à alfabetização da ala ideológica do governo foram nomeadas. Entre elas, William Ferreira da Cunha, que atua na secretaria de Alfabetização do Ministério da Educação (MEC), comandada pelo olavista Carlos Nadalim; e os professores com pesquisas na área Fernando Capovilla e Augusto Buchweitz. Teve também Amábile Pácios, vice-presidente da Federação Nacional de Escolas Particulares. Na câmara da educação superior, tem Aristides Cimadon, reitor da Universidade do Oeste de Santa Catarina (Unoesc); Wilson de Matos Silva, dono da Unicesumar; José Barroso Filho, ministro do Superior Tribunal Militar; e Anderson Luiz Bezerra da Silveira, professor da Universidade Federal Rural do Rio de Janeiro (UFRRJ) (NUNES, 2020). 
Vejam que o movimento direitista se amplia e ocupa espaços de decisões que comprometem a educação de milhares de brasileiros. Ao proclamar a neutralidade da educação diante da política, o objetivo do governo

\begin{abstract}
é o de estimular o idealismo dos professores fazendo-os acreditar na autonomia da educação em face da política, o que os fará atingir o resultado inverso ao que estão buscando: em lugar de estar preparando seus alunos para atuar de forma autônoma e crítica na sociedade, estarão formando para ajustá-los à ordem existente e aceitar as condições de dominação às quais estão submetidos (SAVIANI, 2020, p. 15)
\end{abstract}

Mas, devemos buscar em nossos intelectuais e em especial em nosso patrono da educação o movimento que resiste e luta para impedir a perversidade do capital e da elite conservadora que opera as relações de controle de acordo com as suas necessidades individuais. É preciso se organizar enquanto classe e superar a desesperança que atingi o povo brasileiro. Uma vez que, "a esperança é um condicionamento indispensável à experiência histórica. Sem ela, não haveria história, mas puro determinismo. Só há história onde há tempo problematizado e não pré-dado. A inexorabilidade do futuro é a negação da história" (FREIRE, 2011, p. 71)

\title{
REFERÊNCIAS
}

ALMEIDA, Silvio Luiz de. Neoconservadorismo e liberalismo. In: Gallego, Esther. O ódio como política: a reinvenção das direitas no Brasil. São Paulo: Boitempo Editorial, 2018.

ANDERSON, Perry. O Brasil de Lula. Novos estud. - CEBRAP, São Paulo, n. 91, p. 23-52, novembro de $2011 . \quad$ Disponível em $\leq$ http://www.scielo.br/scielo.php?script=sci arttext\&pid=S0101-

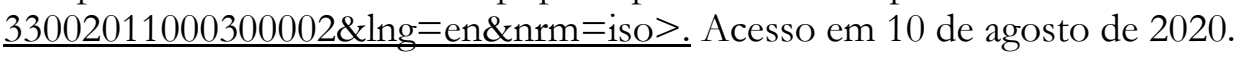

APPLE, Michel. Educando à direita: mercados, padrões, Deus e desigualdade. Cortez: Instituto Paulo Freire, 2003.

ARROYO, Miguel. Paulo Freire: outro paradigma pedagógico? Educação em Revista, Belo Horizonte, v. 35, e214631, 2019. Disponível em <http://www.scielo.br/scielo.php?script=sci arttext\&pid=S010246982019000100202\&lng $=$ en \& $\underline{\mathrm{nrm}=\mathrm{iso}}>$. Acesso em 05 de agosto de 2020. Epub 27 de maio de 2019.

BERTRAND, Yves. Teorias da educação. $2^{\mathrm{a}}$ ed. Lisboa: Instituto Piaget, 2001.

BRANDÃO, Carlos Rodrigues. História do menino que lia o mundo. São Paulo: Expressão Popular, 2014.

BOLSONARO, Jair. Quem assumir em 2019 terá o grande desafio de acabar com o avançado processo de formação de militantes e massa de manobra implementado pela esquerda para o aumento de seu poder e controle. Quando nossa prioridade for o conhecimento, aí sim teremos a garantia de um futuro melhor! Brasil, 15 fev. 2018, 5:20 pm. Twitter: @jairbolsonaro. Disponível em: < bttps:// twitter.com/jairbolsonaro/status/964217823408152579> Acesso em 15 jul. 2020.

BRESSER-PEREIRA, Luiz Carlos. Crise e recuperação da confiança. Revista Econômica Política, São Paulo, v. 29, n. 1, pág. 133-149, março de 2009. Disponível em $\leq$ http://www.scielo.br/scielo.php?script $=$ sci arttext\&pid=S0101-

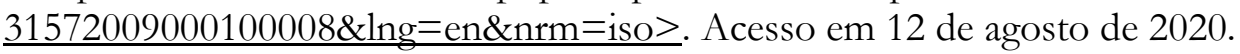


BTG PACTUAL DIGITAL. Investimentos: Liquidez: o que é e para que serve. Blog BTG Pactual digital, 06 abr. 2017. Disponível em: < https://www.btgpactualdigital.com/blog/investimentos/oque-e-liquidez? > Acesso em: 12 ago. 2020.

CARVALHO, Olavo de. Descontruindo Paulo Freire. Estados Unidos, 1 ago. 2017, 12:13 am. Twitter: (a)OdeCarvalho.

Disponível

em: < https://twitter.com/odecarvalho/status/892403039243571206> Acesso em 25 jul. 2020.

CECHIN, Alícia; MONTOYA, Marco Antônio. Origem, causas e impactos da crise financeira de 2008. Revista Teoria e Evidência Econômica, v. 23, n. 48, 8 set. 2017.

COSTA, Camila. 'Brasil nunca aplicou Paulo Freire', diz pesquisador. BBC Brasil, São Paulo, 24 jul. 2015.

$<$ bttps://wmw.bbc.com/portuguese/noticias/2015/07/150719 entrevista romao paulofreire cc > Acesso em: 01 ago. 2020.

DAS AGÊNCIAS. "PSDB contesta a reeleição de Dilma". Gažta do Povo, Curitiba, 30 out. 2014. Disponível em: < https://www.gazetadopovo.com.br/vida-publica/psdb-contesta-a-reeleicao-dedilma-eflg7jua9jt04gy7xpwpffsy6/> Acesso em: 01 ago. 2020.

FERRAZ, Ana Targina Rodrigues. Movimentos sociais no Brasil contemporâneo: crise econômica e crise política. Serv. Soc. Soc., São Paulo, n. 135, pág. 346-363, agosto de 2019. Disponível em $\leq$ http://www.scielo.br/scielo.php?script $=$ sci arttext\&pid=S0101-

66282019000200346\&lng=en\&nrm=iso $>$. Acesso em: 10 de agosto de 2020. Epub, 20 de maio de 2019.

FREIRE, Paulo. Pedagogia da Autonomia: saberes necessários à prática educativa. São Paulo: Paz e Terra, 2011.

FREIRE, Paulo. Pedagogia do oprimido. Rio de Janeiro: Paz e Terra, 42 ed.,2005.

G1. 'Eu, por mim, botava esses vagabundos todos na cadeia, começando no STF', diz ministro da Educação em reunião. G1, Brasília, 22 mai. 2020. Disponível em: <https://g1.globo.com/politica/noticia/2020/05/22/eu-por-mim-botava-esses-vagabundostodos-na-cadeia-comecando-no-stf-diz-ministro-da-educacao-em-reuniao.ghtml $>$ Acesso em: 15 jul. 2020.

GADOTTI, Moacir; ABRÃO, Paulo. Apresentação. In: Instituto Paulo Freire e Comissão De Anistia (orgs.). Paulo Freire, anistiado político brasileiro. São Paulo: Editora e Livraria Instituto Paulo Freire; Brasília: Comissão de Anistia. Ministério da Justiça, 2012. Disponível em: $\leq$ https://www.justica.gov.br/central-de conteudo/anistia/anexos/paulofreire anistiado-1.pdf $>$. Acesso em: 01 ago. 2020.

GADOTTI, Moacir (org.). Paulo Freire: uma biobibliografia. São Paulo: Instituto Paulo Freire, 1996. Disponível em:

http://acervo.paulofreire.org:8080/jspui/bitstream/7891/3078/1/FPF PTPF 12 069.pdf> Acesso em: 30 jul. 2020.

GOUVÊA, Marina Machado. A culpa da crise não é do vírus. In: MOUREIRA, Eliane [et al.] (orgs.). Em tempos de pandemia: propostas para defesa da vida e de direitos sociais. Rio de Janeiro: URJ, Centro de Filosofia e Ciências Humanas, Escola de Serviço Social, 2020.

HADDAD, Sergio. Por que o Brasil de Olavo e Bolsonaro vê em Paulo Freire um inimigo. Folha de São Paulo, São Paulo, 14 abr. 2019. Disponível em: < https://www1.folha.uol.com.br/ilustrissima/2019/04/por-que-o-brasil-de-olavo-e-bolsonaro-veem-paulo-freire-um-inimigo.shtml?origin=folha $>$ Acesso em: 10 ago. 2020. 
HERMIDA, Jorge. Fernando; ORSO, Paulo José. Apresentação: Políticas educacionais e o avanço da nova (ou extrema?) direita. Roteiro, v. 45, p. 1-8, 10 jun. 2020.

KONDER, Leandro. Introdução ao fascismo. São Paulo: Expressão Popular, 2009.

LIRA, Jailton de Souza; HERMIDA, Jorge Fernando. Política Educacional e Neoliberalismo: a educação em alagoas durante o governo Vilela Filho (2007-2014). João Pessoa: Editora UFPB, 2017.

MACHADO, Eliel. Governo Lula, neoliberalismo e lutas sociais. Lutas Sociais, [S.l.], n. 21/22, p. 23-34, jun. 2009. Disponível em: < https://revistas.pucsp.br/ls/article/view/18598>. Acesso em: 11 ago. 2020.

MARX, Karl; ENGELS Friedrich. Manifesto do Partido Comunista. São Paulo: Expressão Popular, 2008.

MARIÁTEGUI, J.C. Biología del fascismo. Lanús Oeste: Nuestra América, 2012.

NUNES, Maíra. Bolsonaro nomeia 7 indicados de Weintraub ao Conselho Nacional de Educação. Correio Braziliense, 10 jul. 2020.2 Disponível em: $<$ https://www.correiobraziliense.com.br/app/noticia/politica/2020/07/10/interna politica,871 235/bolsonaro-nomeia-7-indicados-de-weintraub-ao-conselho-nacional-de-educ.shtml $>$ Acesso em: 10 ago. 2020.

Antes de anunciar o novo ministro da Educação, o presidente Jair Bolsonaro nomeou 12 membros novos ao CNE e causou revolta entre organizações do setor

REDAÇÃO. Bolsonaro sobre Paulo Freire: "Esse energúmeno aí, ídolo da esquerda". Revista Fórum, Brasília, 16 dez. 2019. Disponível em: <https://revistaforum.com.br/politica/bolsonarosobre-paulo-freire-esse-energumeno-ai-idolo-da-esquerda/> Acesso em 05 jun. 2020.

SAVIANI, Dermeval. Políticas educacionais em tempos de golpe: retrocessos e formas de resistência. Roteiro, v. 45, p. 1-18, 3 jun. 2020.

SAVIANI, Dermeval. História das Ideias Pedagógicas no Brasil. São Paulo: Autores Associados, 2011.

SOARES, Sávia Bona. O coronavírus e a modernização conservadora da educação. In: SOARES et al. (orgs.). Coronavírus, educação e luta de classes no Brasil. Brasil: Editora Terra Sem Amos, 2020. p. 5-14.

STANLEY, Jason. Como funciona o fascismo. Porto Alegre: L\&PM, 2018.

STREIT, Maíra. Professor cria polêmica em protesto contra Paulo Freire: "Pedagogia do Oprimido é coitadismo". Revista Fórum, Brasília, 19 mar. 2015. Disponível em: $<$ https://revistaforum.com.br/noticias/professor-cria-polemica-em-protesto-contra-paulofreire-pedagogia-do-oprimido-e-coitadismo/> Acesso em: 01 ago. 2020.

TERRA, Fundador suspende 'Escola Sem Partido' e critica Bolsonaro. Terra: Educação, 19 jul. 2019. Disponível em: < https://www.terra.com.br/noticias/educacao/sem-apoio-fundador-doescola-sem-partido-anuncia-suspensao-de-atividades-e-critica-

bolsonaro,8958d117da38282fee67e3daebe81d19al3d89pi.html> Acesso em: 10 ago. 2020.

WEINTRAUB, Abraham. Paulo Freire e kit gay não têm vez no MEC do Pres. @jairbolsonaro. Vejam uma amostra do formato/conteúdo do material que o professor @CarlosNadalim preparou para as crianças. Querem saber mais? Sigam o prof. @CarlosNadalim, o novo rosto (e o primeiro sorriso) do ensino no Brasil. Brasil, 05 mar. 2020, 6:04 am. Twitter: @ AbrahamWeint. Disponível em: <https://twitter.com/AbrahamWeint/status/1235491283000528896> Acesso em 15 jul. 2020 . 
DOI: $10.12957 /$ teias.2021.62056

ZILIO, Jacson; MIRANDA, Eduardo. Bolsonarismo em tempos de pandemia: entre o fascismo e a barbárie. Jornal GGN, 19 mai. 2020. Disponível em: < https://jornalggn.com.br/artigos/bolsonarismo-em-tempos-de-pandemia-entre-o-fascismo-e-abarbarie-por-jacson-zilio-e-eduardo-miranda/> Acesso em 01 jul. 2020.

\section{Informações dos autores}

Rafael de Farias Ferreira

Universidade Federal da Paraíba

E-mail: rafael.educ.pb@gmail.com

ORCID: https://orcid.org/0000-0001-5210-2365

Link Lattes: http://lattes.cnpq.br/8704111253995663

Jorge Fernando Hermida

Universidade Federal da Paraíba

E-mail: jorgefernandohermida@yahoo.com.br

ORCID: https://orcid.org/0000-0003-1963-4639

Link Lattes: http://lattes.cnpq.br/5339043311979485 